\title{
Can Reasons be Self-Undermining?
}

\author{
Rob Van Someren Greve
}

Received: 15 April 2011 /Revised: 21 June 2011 / Accepted: 11 July 2011 /

Published online: 23 July 2011

(C) The Author(s) 2011. This article is published with open access at Springerlink.com

\begin{abstract}
The characterization of objective, normative reasons to $\varphi$ as facts (or truths) that count in favor of $\varphi$-ing is widely accepted. But are there any further conditions that considerations which count in favor of $\varphi$-ing must meet, in order to count as a reason to $\varphi$ ? In this brief paper, I consider and reject one such condition, recently proposed by Caspar Hare.
\end{abstract}

Keywords Practical reasons $\cdot$ Practical reasoning $\cdot$ Deliberation

The characterization of objective, normative reasons to $\varphi$ as facts (or truths) that count in favor of $\varphi$-ing is widely accepted. ${ }^{1}$ But are there any further conditions that considerations which count in favor of $\varphi$-ing must meet, in order to be a reason to $\varphi$ ? Caspar Hare (2011) recently proposed one such condition: reasons cannot be selfundermining. He relies on this restriction on facts (or truths) which are eligible to be reasons when arguing that there is a distinction between two different ways of thinking about what we objectively ought to do: the 'ought of omniscient desire' and the 'ought of most reason': some facts (or truths) are reasons for desiring that an agent perform an action, but they fail to be reasons for those agents to perform the actions in question. The distinction between two ways of thinking about the objective 'ought' is in turn put to use in arguing for solutions to some outstanding problems in normative ethics. ${ }^{2}$ In this brief paper, I consider and reject Hare's proposed restriction on what can be a reason.

\footnotetext{
${ }^{1}$ See, among others, Dancy (2000), Parfit (2011), Scanlon (1998), and Schroeder (2008).

${ }^{2} \mathrm{He}$ suggests that once the distinction between these two ways of thinking about what we objectively ought to do is born in mind, it turns out that there is, first, a good reply to the so-called 'cluelessness objection' to objective forms of act-consequentialism (cf. Lenman 2000) and second, a satisfactory way to resolve a puzzle about parenthood. See Hare (2011: 199-203) for elaboration of these last two points.
}

R. Van Someren Greve $(\bowtie)$

Department of Philosophy, University of Amsterdam, Amsterdam, the Netherlands

e-mail: r.w.j.vansomerengreve@uva.nl 
Hare offers the following, somewhat intricate example to illustrate his proposals. Imagine that you can spin a wheel of fortune; if you spin and get a black, you get nothing; if you spin and get a red, you get $\$ 100$; if you turn the offer down, you get $\$ 20$. Nothing but the prize you will receive is relevant to your decision. What do you have most reason to do, accept or decline? Provided we are inquiring into your objective, normative reasons to act, the answer to this question is plausibly thought to depend on what will happen, were you to accept and spin the wheel. If you will get a black if you spin the wheel, you have most reason to turn the offer down, as $\$ 20$ dollars is better than nothing; if instead you will get a red if you spin, you have most reason to accept it, as $\$ 100$ is better than $\$ 20$.

According to Hare, this impression is mistaken: even if 'if you spin, you will get a black' is already true prior to acting, and you know that it is true, you still have most reason to accept, because the seemingly decisive consideration 'if you spin, you will get a black,' true though it is, is not a good reason for you to decline the offer. This consideration fails to be a reason for you to take the offer because this consideration is self-undermining, and reasons are not self-undermining, in the following sense:

Reasons are not Self-Undermining (RSU): It cannot be that $c$ is a reason for you to $\varphi$ and yet, if you $\varphi$, then $c$ will not be true (2011: 196).

How does RSU bear on Hare's example? The crucial point is that the claim 'if you spin, you will get a black' is true only if it is also true that you will in fact spin the wheel; if you do not spin the wheel, then there is no fact of the matter about what would have happened if you had spun it. This claim is only true if you in fact spin because whether you will get a black or a red if you spin depends on exactly how you spin the wheel (the exact force you apply to the wheel in doing so, etc.). There is only a fact of the matter about the exact way in which you spin the wheel if you in fact spin, and so only then can there be a fact of the matter about whether you will get a black or a red if you spin. ${ }^{3}$ If you do not spin the wheel, there is no fact of the matter about what would have happened had you spun; this is just a different way of saying that if you decline the offer, 'if you spin, you will get a black' will not be true.

If, as Hare suggests, reasons are not self-undermining, then 'if you spin, you will get a black' thus fails to be a reason for you to decline the offer; once this (seemingly decisive) consideration against acceptance is excluded, the balance of reasons favors acceptance. It is, though, a reason for an omniscient onlooker to desire that you decline the offer; this is how the two ways of thinking about the objective 'ought' come apart. I do not think the argument is successful, because reasons can be self-undermining. In fact, many excellent reasons are self-undermining in the sense defined. Here are three examples:

(1) Alice needs help. That Alice needs help is a reason for Bernie to help her. If Bernie helps Alice, then it will not be true that Alice needs help.

\footnotetext{
${ }^{3}$ The more general point is that the antecedent of 'if you spin, you will get a black' is not specific enough when it is not true at the actual world: if we assume that you do not in fact spin, the set of nearest possible worlds in which 'you spin' is true will include both worlds in which you get a red and worlds in which you get a black; this means that the conditional is not true on the assumption that you do not spin the wheel. Furthermore, underspecification is resilient under embedding: even if 'if you spin, you will get a black' is true at the actual world (assuming that you do in fact spin), 'if you do not spin, then if you would have spun, you would have gotten a black' is still not true. See Hare (2011: 190-93) for discussion.
} 
(2) Charlene is hungry. That Charlene is hungry is a reason for her to eat the sandwich in front of her. If Charlene eats the sandwich in front of her, then it will not be true that she is hungry.

(3) David is in pain. That David is in pain is a reason for him to take a painkiller. If David takes a painkiller, then it will not be true that he is in pain.

In all three cases, the consideration cited as a reason is self-undermining in precisely the way that RSU claims they cannot be if they are in fact a reason, yet these considerations all seem excellent reasons for performing the actions in question. In defense of RSU, Hare could either deny that the considerations cited as reasons in (1)-(3) are genuine reasons to act in certain ways, or he could restrict RSU's application, and hold that while for some values for $c$ (such as the ones cited in (1)-(3)), $c$ can indeed be a reason despite being self-undermining, but that for some other values for $c$ (such as the one cited in the wheel of fortune example), this is not the case. ${ }^{4}$ A closer look reveals that neither of these options is promising.

Denying that the considerations cited in (1)-(3) are reasons to act in the indicated ways is not without cost, as this denial seems to conflict with intuitive assessments about what is and what is not a good reason: on the face of it, these considerations are excellent reasons to perform the acts in question. More importantly, however, is that doing so is unwarranted given the motivation Hare offers for RSU, which appeals to the role that practical reasons must be capable of playing in good practical reasoning 5 :

Considerations are eligible to be reasons only if they can play a role in good practical reasoning, only if they are the kind of considerations that can move a good practical reasoner to act (2011: 196).

The considerations cited as reasons in (1)-(3) are, I take it, the kind of considerations that can-and would - move good practical reasoners to act in the indicated ways: Bernie would surely be reasoning well if he is moved to help Alice on the basis of 'Alice needs help', and the same can be said about Charlene and David. If anything, these agents would be bad practical reasoners if they were not moved to act by the considerations cited in (1)-(3). Therefore, these considerations do

\footnotetext{
${ }^{4}$ It may appear that it can also be denied that the examples offered in the text are genuine counterexamples, because they can be described in such a way that the reasons for these agents to act in the indicated ways are not self-undermining. For instance, in (3), we may be tempted to say that the consideration 'David desires to be free from pain' is a reason for him to take a painkiller. If he takes a painkiller, he will be free from pain, but presumably this change in his condition need not extinguish the relevant desire, and so it is not the case that 'David desires to be free from pain' would be false, were he to act in the way this consideration supports. Does the fact that we also can describe the situation in this way undermine its force as a counterexample to RSU? I think not: the conclusion that (3) fails as a counterexample requires not just the observation that the situation can be described in this way, but that that is the only correct way to describe it. Put differently, to show that (3) fails, it needs to be established that only 'David desires to be free from pain' constitutes a reason for David to take a painkiller, and that 'David is in pain' does not. On the face of it, both considerations can correctly be cited as a reason; what ground is there to deny this? Furthermore, even if we could be persuaded that we need to choose between them, it is all but clear that the former is preferable: that the agent has a desire to be in a state that can be realized by an action is perhaps better construed as a background condition on there being a reason, instead of as the reason itself (compare Schroeder 2008: 23-40). Thanks to an anonymous referee for pressing me on this point.

${ }^{5}$ Motivating conditions on what can be a reason by appeals to the quality of the reasoning that relies on the consideration put forward as a reason is not uncommon; see for instance Setiya (2007).
} 
count as reasons. Given that these considerations are both reasons and selfundermining, RSU in its current formulation is false: reasons can be self-undermining.

Can a restricted version of RSU be defended? Restricting may look like a good move at first sight; after all, the considerations cited in (1)-(3) appear to be different in kind from the consideration that Hare wants to rule out in the wheel of fortune case. Perhaps, then, only some of our reasons cannot be self-undermining. The main problem facing a restricted version of RSU is that the result may turn out to not do any work. Here is why. If being self-undermining does not entail that a consideration is not a reason, then while there may well be some identifiable, non-empty set of considerations bearing (favorably or unfavorably) on certain actions, the elements of which are both (a) self-undermining and (b) not reasons to perform the actions that they bear on, what ground is there for holding that it is the fact that they are selfundermining which explains why they are not reasons?

Call whatever property it is that the elements of this set share which is not shared by self-undermining considerations that are reasons ' $X$.' If (as I have suggested) being self-undermining does not disqualify considerations from being a reason across the board, then it is either instantiating both the property of being selfundermining and the property of being $X$ that explains why these considerations are not reasons, or some it is other property the elements of the set share which does the explanatory work; call this latter property ' $Y$.' If there is some property that we can fill in for $Y$, a restricted version of RSU comes out as a theoretically idle wheel. If the former, we need some story explaining why the combination of being selfundermining and being $X$ disqualifies considerations from being reasons, a story on which it does not turn out that their being $X$ explains why these considerations are not reasons, for in that case, the restricted version of RSU is also an idle wheel.

Is there a property that fits this bill? I do not have an argument that establishes that there cannot be such a property, but these brief remarks indicate what a successful defense of a restricted version of RSU would need to achieve. To my mind, it is unlikely that, given the rather stringent conditions for success just sketched, such a defense is forthcoming. I therefore conclude that for now at least, we can reasonably reject RSU altogether, and maintain that all kinds of reasons can be self-undermining.

Acknowledgement Thanks to an anonymous referee for helpful comments.

Open Access This article is distributed under the terms of the Creative Commons Attribution Noncommercial License which permits any noncommercial use, distribution, and reproduction in any medium, provided the original author(s) and source are credited.

\section{References}

Dancy, J. (2000). Practical reality. Oxford: Oxford University Press.

Hare, C. (2011). Obligation and regret when there is no fact of the matter about what would have happened if you had not done what you did. Nô̂s, 45(1), 190-206.

Lenman, J. (2000). Consequentialism and cluelessness. Philosophy \& Public Affairs, 29(4), 342-370.

Parfit, D. (2011). On what matters. Oxford: Oxford University Press.

Scanlon, T. (1998). What we owe to each other. Cambridge: Harvard University Press.

Schroeder, M. (2008). Slaves of the passions. Oxford: Oxford University Press.

Setiya, K. (2007). Reasons without rationalism. Princeton: Princeton University Press. 